\section{(6) OPEN ACCESS}

\title{
'Treatment of the Sportsman's groin': British Hernia Society's 2014 position statement based on the Manchester Consensus Conference
}

\author{
Aali J Sheen, ${ }^{1}$ B M Stephenson, ${ }^{2}$ D M Lloyd ${ }^{3}$ P Robinson, ${ }^{4}$ D Fevre, ${ }^{5}$ H Paajanen, ${ }^{6}$ \\ A de Beaux ${ }^{7}$ A Kingsnorth, ${ }^{8}$ O J Gilmore, ${ }^{9}$ D Bennett, ${ }^{10}$ । Maclennan, ${ }^{1} \mathrm{P}$ O'Dwyer, ${ }^{11}$ \\ D Sanders, ${ }^{8}$ M Kurzer $^{12}$
}

For numbered affiliations see end of article.

\section{Correspondence to} Aali J Sheen, Honorary Senior Lecturer, University of Manchester and Consultant Surgeon, Department of Surgery, Central Manchester Foundation Trust, Manchester Royal Infirmary, Manchester M13 9WL, UK:

Aali.sheen@cmft.nhs.uk

Accepted 24 September 2013 Published Online First 22 October 2013
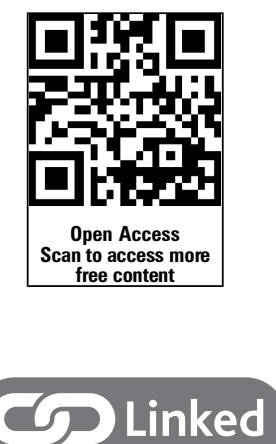

- http://dx.doi.org/10.1136/ bjsports-2013-092958

CrossMark

To cite: Sheen AJ Stephenson BM, Lloyd DM, et al. Br J Sports Med 2014;48:1079-1087.

\section{ABSTRACT \\ Introduction The aim was to produce a} multidisciplinary consensus to determine the current position on the nomenclature, definition, diagnosis, imaging modalities and management of Sportsman's groin (SG).

Methods Experts in the diagnosis and management of SG were invited to participate in a consensus conference held by the British Hernia Society in Manchester, UK on 11-12 October 2012. Experts included a physiotherapist, a musculoskeletal radiologist and surgeons with a proven track record of expertise in this field. Presentations detailing scientific as well as outcome data from their own experiences were given. Records were made of the presentations with specific areas debated openly.

Results The term 'inguinal disruption' (ID) was agreed as the preferred nomenclature with the term 'Sportsman's hernia' or 'groin' rejected, as no true hernia exists. There was an overwhelming agreement of opinion that there was abnormal tension in the groin, particularly around the inguinal ligament attachment. Other common findings included the possibility of external oblique disruption with consequent small tears noted as well as some oedema of the tissues. A multidisciplinary approach with tailored physiotherapy as the initial treatment was recommended with any surgery involving releasing the tension in the inguinal canal by various techniques and reinforcing it with a mesh or suture repair. A national registry should be developed for all athletes undergoing surgery.

Conclusions ID is a common condition where no true hernia exists. It should be managed through a multidisciplinary approach to ensure consistent standards and outcomes are achieved.

\section{INTRODUCTION}

Over the last four decades, the condition of chronic pain in an athlete's groin, sometimes described as a Sportsman's groin (SG) or inguinal disruption (ID) has been attributed to a hernia, a groin disruption, an incipient hernia or 'athletic pubalgia' as well as a simple chronic groin pain. ${ }^{1} 2$ There has been no clear consensus on this condition, especially on its nomenclature (SG or ID), which has been regarded as difficult to accurately diagnose and manage. ${ }^{3} 4$ Many athletes, elite and amateur, can be affected by groin pain, which is also prevalent in non-athletes. ${ }^{5}$ Cyclists and swimmers are less commonly affected as these sports do not lead to the increased pelvic and torso movements that are known to predispose to a painful groin. ${ }^{6}$ Chronic groin pain is most often found in athletes who undertake sports involving kicking and twisting movements while running. ${ }^{7}$ The pain is often experienced at the common point of origin of the rectus abdominis muscle and the adductor longus tendon on the pubic bone and the insertion of the inguinal ligament on the pubic bone. ${ }^{5}$ Furthermore, it is important to remember that there is to date no clear consensus as to what specifically constitutes this diagnosis ${ }^{8}$ and in addition it has been recognised that treatment relies on both conservative measures as well as open and laparoscopic surgical approaches. ${ }^{9}$

It is well recognised from previous studies and areas of research in this field that a careful history and examination are required as other possible causes of chronic groin pain must ideally be excluded. These include adductor muscle injuries, osteitis pubis and pubic symphysitis although it is also accepted that they can coexist with an ID. ${ }^{7} 10$ Following the history and physical examination, some musculoskeletal investigations such as ultrasound or MRI may be helpful in evaluating these patients and ruling out other pathologies, ${ }^{11-14}$ although no radiographic study can rule out ID. ${ }^{15}$ Bone marrow oedema, osteitis pubis, tendon disruption as well as fluid in the symphysis have all been described to be present in varying degrees in this cohort of patients through MRI findings. ${ }^{16} 17$

In an effort to better define the pathophysiology, nomenclature, diagnostic modalities used, conservative treatment options and the most appropriate surgical options available as well as to consider the development of a national registry, the British Hernia Society (BHS) convened a meeting of recognised chartered physiotherapists, musculoskeletal radiologists and surgeons with an interest in this difficult subject.

This meeting took place in October 2012, in Manchester, UK with an audience of 150 surgeons.

\section{Statement on background to consensus process Conference}

In Manchester in October 2012, as part of the BHS annual scientific meeting a plenary session was dedicated to produce the first consensus statement on the management of groin pain in athletes, which is commonly described as a Sportsman's hernia or groin. To this end, a range of experts in this field were invited and asked to present their experiences and data in their area of practice. Prior to the 
meeting the speakers were consulted with an agreement made on the specific questions that were to be asked. The questions were aimed at areas not fully addressed on the SG in the literature to date. The meeting used the term SG throughout the discussion in order to maintain the use of a well recognised description for chronic or persistent groin pain experienced by athletes.

The basic principles governing the conduct of a consensus development conference are summarised below:

1. All the invited panellists provided keynote lectures in their area of expertise.

2. The panellists were drawn from a multidisciplinary field of clinical practice in the field of sports-related groin pain. They do not represent organisations per se but were selected for their expertise, experience and understanding of this field.

3. Each lecture was supplemented by a panel discussion with an open audience forum in an attempt to forge a consensus on eight key questions.

4. Prior to the conference a literature review was undertaken by the Board of the Society, to identify controversial points in the literature regarding the management of SG using biomedical databases through the PUBMED platform.

5. The panellists were all contacted prior to the meeting to ascertain the extent of their lectures.

6. All the panellists were given access to the key questions to be asked at the consensus statement.

7. A systematic literature review was prepared for use in addressing the conference questions.

8. The consensus statement is intended to serve as the scientific record of the conference.

9. The consensus statement will be widely disseminated to achieve maximum impact on both current practice and to aid in future medical research.

10. The panel Chairperson (AJS) did not identify with any advocacy position. The Chairperson was responsible for directing the consensus session and guiding the panel's deliberations.

\section{Consensus meeting literature review}

1. Searches were performed independently by two members of the BHS board using relevant medical subject headings and free-text terms. No language restrictions were applied to the searches. Both generic and specially developed search filters were employed when necessary. Databases searched were MEDLINE (1966 onwards), EMBASE (1980 onwards), Cochrane Central Register of Controlled Trials (4th Quarter 2004), Cochrane Database of Systematic Reviews (4th Quarter 2004), Database of Abstracts of Review of Effects (4th Quarter 2004), and Cumulative Index to Nursing \& Allied Health Literature (1982 onwards).

2. There was no systematic attempt to search grey literature (conferences, abstracts, thesis and unpublished trials). Hand searching of journals not indexed on the biomedical databases was not carried out.

3. A preliminary scrutiny of titles and abstracts was undertaken and full copies of publications that addressed the clinical questions were obtained.

4. Following a critical appraisal of each publication, studies that did not report relevant outcomes or were not relevant to a particular clinical question were excluded. Searches were returned prior to the meeting, thereby including evidence published and included in the literature databases up to October 2012.

5. This date should be considered the starting point for searching for new evidence for future updates to this consensus statement.

\section{Consensus presentations}

Six keynote lectures were given on three topics to a learned audience of predominantly hernia surgeons.

The topics included were

1. Physiotherapy and active sports rehabilitation (DF)

2. Imaging investigations (PR)

3. Four lectures on surgical techniques and indications (HP, IM, OJG and DML)

\section{Consensus questions}

After all the lectures, the speakers were all invited for their respective opinions on the following questions:

1. What appropriate nomenclature would be acceptable for this condition?

2. What pathology if any is present?

3. What imaging modalities or diagnostic techniques are advised?

4. Is surgery always advised?

5. If yes to surgery, then what operation should be undertaken?

6. What other treatment modalities would you use?

7. What repair would you undertake for a primary presentation?

8. What repair or management would you recommend for a recurrence?

\section{Consensus document}

This manuscript first lists all the specific questions that were raised at the meeting.

Second, all questions are followed by the four specific areas discussed at the meeting including:

A. Definition of the condition commonly described as SG

B. Physiotherapy techniques employed

C. Imaging investigations undertaken

D. Surgical procedures carried out

These headings are followed by a review of the literature encompassing the key presentations at the meeting followed by the views of the panellists on the relevant consensus questions.

The consensus was reached at the end of each discussion by a majority of the panel reaching an agreement, in all cases a unanimous conclusion was reached.

Finally a summary and final conclusion is presented with recommendations for future research.

\section{A. Consensus questions on definition and pathology}

1. What appropriate nomenclature would be acceptable for this condition?

2. What pathology if any is present?

Question 1 response-What appropriate nomenclature would be acceptable for this condition?

The conference audience and panel were presented with the terms athletic pubalgia, sports hernia, incipient hernia, Gilmore's groin, ID, groin disruption and SG as possible nomenclatures used to describe the condition of a painful groin in elite athletes. The entire panel agreed that the term 'hernia' should not be used as a hernia, in every definition of this term, is rarely found in elite and amateur athletes.

The agreed term to be used for this condition is ID as this was thought to accurately describe the condition which tends to present with an increase in tension in the groin area due to the high level of 'twisting, turning, sprinting and kicking' the athletes undertake in their sporting activity. 


\section{Summary of nomenclature}

The agreed term to be used for this condition is ID as this was thought to accurately describe the condition which tends to present with an increase in tension in the groin area due to the high level of 'twisting, turning, sprinting and kicking' the athletes undertake in their sporting activity.

\section{Definition of ID in athletes}

In the literature to date there have been many descriptions provided for the condition commonly described as SG such as athletic pubalgia, incipient hernia, pubic inguinal pain syndrome and ID. ${ }^{1-4}$ It is generally understood that ID is a condition recognised by groin pain and is commonly seen in very active sports persons. It is also noted in literature that other pathologies also account for the symptoms of groin pain, these include adductor muscle tendinitis, osteitis pubis and pubic symphysitis, although it is also accepted that they can coexist with ID. ${ }^{7} 8$

ID can therefore be defined as pain, either of an insidious or acute onset, which occurs predominantly in the groin area near the pubic tubercle where no obvious other pathology, such as a hernia, exists to explain the symptoms. ${ }^{3-9}$

The diagnosis of ID can be made if at least three out of the five clinical signs below are detectable

1. Pinpoint tenderness over the pubic tubercle at the point of insertion of the conjoint tendon;

2. Palpable tenderness over the deep inguinal ring;

3. Pain and/or dilation of the external ring with no obvious hernia evident;

4. Pain at the origin of the adductor longus tendon; and

5. Dull, diffused pain in the groin, often radiating to the perineum and inner thigh or across the midline.

Question 2 response-What pathology if any is present?

The conference concluded that the posterior wall of the inguinal canal was weakened. In some athletes there was also evidence of disruption of the external oblique aponeurosis. The weakness of the posterior wall is the most common finding as previously reported with up to $85 \%$ of athletes showing evidence of this phenomenon. ${ }^{18-20}$ This was noted as either tears evident in the aponeurosis on the anterior or open approach as well as inguinal ligament damage or tears seen at laparoscopy. ${ }^{21}$ The pathology was not always evident in the athletes in every case and care was taken to emphasise that other pathology such as dilation of the external ring, conjoint tendon tears and inguinal ligament dehiscence might also be present. It was agreed that clinical examination is key in assessing such individuals with a consensus that other causes of chronic groin pain must be excluded such as osteitis pubis, pubic rami fractures, bursitis, slipped epiphysis, acetabular injury, femoroacetabular impingement and even early osteoarthritis. ${ }^{22}$ Examination should also aim to elicit any underlying rectus abdominis or adductor longus tendon damage as well as hip pathology although it was accepted that these might also coexist. Pain below and lateral to the inguinal ligament may indicate hip pathology or adductor longus injury with pain above the inguinal ligament more indicative of ID. It was also considered important to rule out disruption of the hamstring muscles as it is documented that an imbalance of core muscles and muscle groups of the thigh may lead to groin pain.

\section{Summary of pathology}

Abnormal tension exists in the inguinal canal due to varying degrees of ID and this is recognised as posterior wall weakness, external ring dilation, conjoint tendon damage and tears in the inguinal ligament. Not all of the features are present in any one individual and other pathologies involving the muscles, ligaments and joints may also be affected.

\section{B. Consensus question on imaging}

3. What imaging modalities or diagnostic techniques are advised?

\section{Review of literature and presentation}

Imaging chronic groin pain in athletes is also a controversial topic. The insidious onset of symptoms is important as groin pain due to an acute muscular, tendinous or osseous injury is easily visualised on imaging and generally carries a much better prognosis than chronic groin pain. Conventional X-rays and CT do not typically aid diagnosis as bone morphology does not correlate with symptoms and as imaging techniques they are insensitive to soft tissue changes and oedema. Herniography and isotope bone scans are now rarely performed and have been superseded by high resolution MRI. Diagnostic laparoscopy is not recommended.

For the purposes of describing imaging features of groin pain in athletes we will consider imaging assessment of the symphysis pubis and inguinal canals separately.

The clinical diagnosis of SG, ID, osteitis pubis listed on a request card for imaging varies greatly between clinicians and their experience. $^{23}$

Most imaging research studies have described symphyseal and parasymphyseal MRI changes with very few studies describing reliable inguinal canal findings. Whether this is selection bias for the athletic cohorts studied or whether it relates to the fact that described inguinal microtears, wall laxity etc cannot be detected on ultrasound or MRI cannot be determined conclusively. ${ }^{11-14}$

\section{SYMPHYSIS PUBIS}

MRI typically shows two patterns of symphysis pubis-based oedema in athletes with groin pain. Grading of oedematous changes is largely subjective ranging from mild to severe. ${ }^{11-13}$

1. Symphyseal bone marrow oedema In this pattern MRI typically shows marked bone marrow oedema involving both pubic bodies and there may be high signal fluid in the joint itself with soft tissue oedema diffusely and symmetrically extending into the surrounding tendons and muscle fibres. $^{12} 14$ This imaging appearance is usually seen in younger athletes (under 20 years of age) and this appearance of extensive oedema (in the bone marrow and soft tissues) differs from that typically seen in skeletally mature athletes with chronic groin pain (see table 2 below).

2. Symphysis capsular and adductor change Compared to the first pattern described above the typical pattern of oedematous abnormality seen in skeletally mature athletes, with groin pain, particularly in football players, is much more localised and typically asymmetrical. MRI shows more focal moderate to marked pubic bone marrow oedema in the subcortical anteromedial pubis. compared to that seen throughout the pubic bodies in the younger athletes described above. There is also oedema involving the adjacent anterior capsule, capsular ligaments and the enthesis of the common aponeuroses of adductor longus and rectus abdominis. Partial capsular and adductor tendon disruption has been termed the 'cleft' sign. ${ }^{13}$ Low grade oedematous change can be commonly seen in all athletes but severer features have been shown to correlate well in athletes with current adductor symptoms. ${ }^{12-14}$ 
Ultrasound of the symphysis pubis and enthesis

Ultrasound is rarely of value as the osseous, capsular and entheseal oedema seen on MRI is not visible on ultrasound. Although ultrasound is accurate for complete or partial adductor tears, these are rarely present in these athletes despite marked soft tissue oedema on MRI. ${ }^{24}$

\section{INGUINAL CANAL}

\section{MRI of the inguinal canal}

The inguinal canal and its surrounding muscles and aponeuroses are well seen on MRI but do not usually demonstrate oedema or structural disruption in athletes with chronic groin pain. Rarely there may be acute disruption but this is always accompanied with the relevant history of acute pain rather than of insidious symptoms. Asymmetry of the abdominal wall muscles is not discriminatory as muscular atrophy can occur after surgery or previous injury and is often asymptomatic. ${ }^{11}$

\section{Ultrasound of the inguinal canal}

Ultrasound of the inguinal canal is also usually normal in many athletes with chronic groin pain. Ultrasound is accurate for detecting true inguinal or femoral hernias but these are rare in athletes. ${ }^{25}$ Abnormal posterior wall movement and ballooning has been described but overall this finding is not sensitive or specific and can be present in some asymptomatic athletes and even after successful inguinal surgery. ${ }^{25}{ }^{26}$ Aponeurotic, fascial or ligament disruption is usually not detected by ultrasound.

\section{RADIOLOGICAL INTERVENTION TECHNIQUES}

The use of injection treatment and choice of injectable material is up to the choice of the clinician depending on whether inflammation, chondral damage, ligamentous 'laxity' is thought to be the cause of the problem. In that case, dry needling, local anaesthetic, sclerosants, cortisone, platelet-enriched plasma, autologous blood and traumeel can be considered on their own or in combination. ${ }^{12}$

The symptomatic relief obtained can be used to progress rehabilitation, however there are no randomised studies for efficacy of injection treatment compared to rehabilitation and/or surgery but some uncontrolled studies have shown significant pain relief in symptomatic athletes with osteitis pubis or adductor-related groin pain ${ }^{27} 28$

\section{Image-guided intervention}

Symphysis pubis articular injection can be performed under fluoroscopic or ultrasound guidance. Soft tissue injection into the capsular and adductor entheseal soft tissue change can be performed using ultrasound guidance. MRI and clinical findings are usually used for targeting the side and specific site if a periarticular injection is to be performed. The imaging interventions were presented at the consensus meeting but no specific discussion was introduced as to when they should be used and at what stage of the treatment in athletes with chronic groin pain.

\section{Question 3 response-What imaging modalities or diagnostic techniques are advised?}

MRI of the groin is the preferred method to diagnose ID. More specifically, it is used to exclude other pathology as there are no unique and reproducible findings, which can define the cause of inguinal pain in athletes. Ultrasound may also provide some benefit. ${ }^{29}$ The discussion agreed that the imaging modalities should only be used to exclude other pathology such as acetabular damage, hip pathology, adductor muscle tears and pubic bone injuries. It is generally accepted that athletes may also have evidence of osteitis pubis, fluid in the symphysis pubis and bone marrow oedema on $\mathrm{MRI}^{16}$ but this does not always equate to any pain experienced in the groin and does not necessarily mean that the athlete will not benefit from groin hernia surgery if the pain symptoms do not resolve after the initial exercise regimes.

\section{Summary of imaging}

It is generally recognised that most radiology studies do not have a well-defined clinical input regarding clinical assessmentthat is, how many athletes have ID, osteitis pubis, adductor longus injury etc.

Groin MRI is the preferred method of imaging in patients with suspected ID. Traditionally it has not been a prerequisite to any surgical treatment intended by the more experienced surgeons, but it was accepted that under the present climate an MRI is almost an inevitable undertaking, especially in elite athletes.

The two MRI patterns that one would expect to see in athletes with groin pain are

1. Young athletes $<18$ years of age-diffuse bilateral oedema which can be equivalent to a stress response;

2. Older athletes $>18$ years of age-more focal oedema in subcortical bone and capsule/enthesis usually bilateral but asymmetrical.

\section{Consensus question on conservative treatment}

4. Is surgery always advised?

The panellist agreed that surgery is not always required and there are alternative rehabilitation treatments that should be considered first.

\section{Physiotherapy and active sports rehabilitation Presentation}

The aim of any treatment in the elite athlete is to minimise the total time the athlete is away from their sporting activity and to improve the player availability for the team. Based on the subjective experience of a premiership football team's physiotherapists, over the last 20 years, due to an improved understanding of the role of abdominal and gluteal stability on the mechanisms of pelvic movement, the need for surgical intervention has reduced (1994-6 repairs/year to 2012—2 repairs/year, unpublished data, D Fevre).

\section{Screening of athletes}

Screening athletes is of vital importance especially looking for variances in gait, posture and flexibility. Functional medical screening in elite athletes has become an important role for medical teams in assisting in injury prevention. The importance of any screening programme is that it is repeatable, functional and prevents the onset or recurrence of injury.

For the general surgeon in the outpatient setting, important aspects of assessment are designed to examine mobility around the hip joints, adductor muscle 'squeeze' test, posterior pelvic tilt assessment, gluteal control and evidence of lumbar lordosis.

\section{Training regimes}

Once the screening assessment is complete athletes should undergo a considerable amount of training designed specifically for the individual. This early part of a 'functional rehabilitation programme' should be taught prior to any surgery so that the athlete has a full understanding of what is expected of them in the weeks following any surgery. In many cases most athletes 
will only understand abdominal work in terms of the number of sit ups or leg raises they can perform, exercises which place an enormous emphasis on rectus abdominis and hip flexor strength and unwanted spinal loading. Emphasis must be placed on the stabilising role the often-neglected internal obliques, transversus abdominis, gluteals and adductors play in terms of functional movement and posture. Research has demonstrated the stabilising effect of isometric contraction of the abdominal muscles in producing strong, yet mechanically effective core abdominal strength and stability. ${ }^{30}$ In the late preoperative/early postoperative phase, emphasis must be placed on maintaining stability in the neutral spine position. This requires time and a thorough explanation of what is required during what appear to be very simple exercises for the 'ill-informed' patient (initial treatment programme summarised in box 1).

\section{Sports rehabilitation}

Throughout the rehabilitation programme it is important to make any rehabilitation work as sport/occupation specific as possible. It must be emphasised that the medical team have a thorough understanding of the demands of the sport/occupa$\operatorname{tion}^{31}$ (box 1). Only then can any rehabilitation programme be designed to assist a full recovery and test when the patient is ready to return to full activity. Appropriate preoperative and postoperative care should allow a full return to activity within

Box 1 Suggested initial treatment programme following diagnosis of inguinal disruption

Individual postural assessment for basis of prehabilitation and rehabilitation programme

Specific tests for range of movement

- Spine

- Hip

- Muscle length

- Myofascial pathways

Strength tests

- Gluteus medius

- Transversus abdominis

- Isokinetic testing of pelvic control and isolated muscle strength

Education of postoperative exercise programme as detailed in week 1 of rehabilitation programme (table 1)

Prehabilitation strengthening programme for

- Gluteus medius/maximus

- Transversus abdominis

- Erector spinae/lateral abdominals/hip flexor/hamstring (if required from assessment)

Use of Swiss balls, core-ex, medicine balls, pulleys and

clinibands

Dynamic stability of posture in standing/sitting and functional activity. This will involve re-education of hypertonic (overactive) and hypotonic (underactive) muscle tissue around the pelvis Increase mobility/lengthening of tight muscle and myofascial structure

Use of foam rollers, tennis and golf balls to release tight

structures

Therapist mobilisation-based work

Cardio vascular-based exercise programmes which support the above dynamic strengthening and lengthening factors

Swimming (good technique) and yoga
Table 1 Proposed rehabilitation regime following operative repair of inguinal disruption

\begin{tabular}{|c|c|}
\hline Week & Procedure \\
\hline 1 & $\begin{array}{l}\text { Initiation of functional rehabilitation programme } \\
\text { Isometric abdominals-emphasis on transversus and oblique's with } \\
\text { pelvic control } \\
\text { Isometric hip flexors, extensors, abductors, adductors and rotators } \\
\text { - Spinal mobilisation programme }\end{array}$ \\
\hline 2 & $\begin{array}{l}\text { Increase walking using time as limiting factor, increasing by } 5 \mathrm{~min} \text { each } \\
\text { day if no ill effectsContinue isometrics and active spinal work, } 10 \text { reps } / 4 \\
\text { times/dayEnd of week initiate active assisted cliniband/isokinetic work in } \\
\text { functional standing position }\end{array}$ \\
\hline 3 & $\begin{array}{l}\text { Functional rehabilitation } \\
\text { Neurological gymnastic ball work } \\
\text { Mobility work, active and passive } \\
\text { Stability work } \\
\text { Hydrotherapy } \\
\text { Cardiovascular } \\
\text { Swimming (if wound healed) } \\
\text { Cycling } \\
\text { Initiate running programme, progressing from aerobic to anaerobic } \\
\text { over the next } 3 \text { weeks } \\
\text { Isokinetics } \\
\text { Submaximal to maximal isometric hip work/isokinetics if available. } \\
\text { Bias towards presurgical isokinetic test results. Once } 25 \% \text { or lower } \\
\text { deficit between limbs, begin active concentric work, starting on fast } \\
\text { speeds (240) progressing to slower (60) depending on daily } \\
\text { reassessment. }\end{array}$ \\
\hline 4 & $\begin{array}{l}\text { Return to active assisted work to re-educate concentric/eccentric } \\
\text { functional pattern.Progression of functional rehabilitation workEarly } \\
\text { sport/occupation-specific rehabilitationRunning } \\
\text { forwards } \rightarrow \text { backwards } \rightarrow \text { cutting } \rightarrow \text { sprinting }\end{array}$ \\
\hline 5 & $\begin{array}{l}\text { Concentric/eccentric lower limb muscle patterns-manual/cliniband/ } \\
\text { isokineticsGeneral weights work with abdominal belt/lumbar supportFull } \\
\text { soccer-specific rehabilitationReturn to play/work according to functional } \\
\text { reassessment }\end{array}$ \\
\hline
\end{tabular}

4-8 weeks from the date of surgery (suggested postoperative programme summarised in table 1). Emphasis must be placed on the need for a close liaison between the treating clinicians and the physiotherapy team, for the preoperative and postoperative rehabilitation, as there is a recognised variance in the surgical techniques undertaken.

\section{Question 4 response-Is surgery always advised?}

As stated above it was agreed that surgery is not always indicated and rehabilitation as well as physiotherapy is strongly recommended for all athletes in the first instance.

\section{Summary of physiotherapy}

A suggestion was made for both an initial treatment regime as a means of conservative or non-operative treatment (box 1).

Table 2 Suggested algorithm for the management of inguinal disruption (ID)

\begin{tabular}{lll}
\hline Time & Discomfort & Treatment \\
\hline $\begin{array}{lll}1- \\
2 \text { months }\end{array}$ & $\begin{array}{l}\text { ID } \\
\text { VAS 0-2 at rest; 6-7 on } \\
\text { exercise; cannot undertake } \\
\text { any sporting activity }\end{array}$ & $\begin{array}{l}\text { Prehabilitation, rest and analgesia } \\
\text { (see box 1) }\end{array}$ \\
$>2$ months & $\begin{array}{l}\text { On going ID -chronic groin } \\
\text { pain-failure of } \\
\text { rehabilitation }\end{array}$ & $\begin{array}{l}\text { Surgical repair either open or } \\
\text { laparoscopic with postoperation } \\
\text { rehabilitation (see table 1) }\end{array}$ \\
\hline VAS, visual analogue scale. &
\end{tabular}


There was also a suggested postoperative rehabilitation programme (table 1). The authors also accepted that there is a need for a treatment algorithm to provide an indication as to when surgery is required (see table 2) It was accepted by the authors that selective discussions in the conservative treatment options with the use of analgesia and anti-inflammatory medication requires a more in-depth discussion.

\section{Consensus questions on surgery}

5. If yes to surgery, then what operation should be undertaken?

1. What other treatment modalities would you use?

2. What repair would you undertake for a primary presentation?

3. What repair or management would you recommend for a recurrence?

\section{Surgical techniques and indications}

Review of literature

No operation to date has been shown to be superior with the open and laparoscopic techniques providing benefit in experienced hands. ${ }^{18} 2131-33$ The role of surgery is to release the abnormal tension in the inguinal canal and reconstruct the weakness in the posterior wall with a mesh.

A recent study compared in a trial setting, whether laparoscopic surgery was more effective than non-operative treatment. ${ }^{10}$ This study randomised 60 athletes (30 each arm) to either a totally extraperitoneal (TEP) repair or conservative measures with 2 months of active physiotherapy, including steroid injections and anti-inflammatory drugs. This study concluded with a reduction in chronic groin pain after 1 month with a 12 -month follow-up in the operative group $(\mathrm{p}<0.001)$, with a return to sporting activity in 3 months greater in the operative arm, but it should be noted that $10 \%$ of patients had undergone an open tenotomy peroperatively (90\% vs $27 \%, \mathrm{p}<0.001) .{ }^{10}$

Indeed trials reporting data on surgery in this subject are limited and seem to focus on adductor-related pain. ${ }^{34-36}$

There are several randomised trials in the area of groin injury but they mostly cover conservative treatment or prevention of adductor-related groin pain and are summarised in table 3. ${ }^{34-37}$

A more recent randomised trial from Australia hypothesised that inflammation and compression around the ilioinguinal nerve was the most likely cause of chronic groin pain in athletes and consequently constructed a study examining the effects of radiofrequency denervation (RFD) of the inguinal ligament compared to local anaesthesia and steroid injections in 36 patients. ${ }^{37}$ This study showed a significantly improved benefit in terms of pain with the use of RFD $(p<0.001)$ with a subgroup of patients finding further short-term improvement from RFD if surgery had failed. ${ }^{37}$

Various surgical techniques have been described including the open repair using a specialised 'darn', ${ }^{33}$ a simple suture repair which does not involve the use of a mesh with little or no tension in the posterior wall therefore allowing the athlete to mobilise early after the surgery. In some cases the genital branch of the genitofemoral nerve is divided particularly if it is found to be under tension. ${ }^{38}$ This German group reported that $67 \%$ of professional athletes returned to full activity at a median of 14 days, although as discussed earlier the presence of 'tension' in the vicinity of the nerve appears not to be a measurable phenomenon. ${ }^{39} 40$ A laparoscopic approach to ID has also been performed by means of a TEP approach. ${ }^{32}$ Interestingly while there was no detectable abnormality in $58 \%$ of the athletes, $93 \%$ of the cases returned to their sporting activities within a month. ${ }^{32}$
Table 3 Summary of randomised controlled trials managing adductor pain and Sportsman's groin

\begin{tabular}{|c|c|c|c|}
\hline Authors & Comparison & Number & Result \\
\hline $\begin{array}{l}\text { Paajanen } \\
\text { et } a l^{10}\end{array}$ & $\begin{array}{l}\text { TEP repair vs active } \\
\text { physiotherapy and } \\
\text { steroid injection }\end{array}$ & $\begin{array}{l}60 \text { (chronic } \\
\text { pain) }\end{array}$ & $\begin{array}{l}\text { Advantage over } \\
\text { operative repair in } \\
\text { return to sporting } \\
\text { activities at } 3 \text { months } \\
(p<0.001)\end{array}$ \\
\hline $\begin{array}{l}\text { Hölmich } \\
\text { et } a l^{34}\end{array}$ & $\begin{array}{l}\text { Active training/ } \\
\text { physiotherapy vs no } \\
\text { active training }\end{array}$ & $\begin{array}{l}68 \text { (adductor } \\
\text { pain) }\end{array}$ & $\begin{array}{l}\text { Advantage over } \\
\text { structured programme } \\
(p=0.006)\end{array}$ \\
\hline $\begin{array}{l}\text { Weir } \\
\text { et } a^{36}\end{array}$ & $\begin{array}{l}\text { Multimodal } \\
\text { programme with } \\
\text { exercise therapy }\end{array}$ & $\begin{array}{l}48 \text { (adductor } \\
\text { pain) }\end{array}$ & $\begin{array}{l}\text { Quicker return to work } \\
\text { with multimodal } \\
\text { treatment }(p=0.043)\end{array}$ \\
\hline $\begin{array}{l}\text { Hölmich } \\
\text { et }\left.a\right|^{35}\end{array}$ & $\begin{array}{l}\text { Structured exercise } \\
\text { programme with } \\
\text { control exercise } \\
\text { programme }\end{array}$ & $\begin{array}{l}977 \text { (adductor } \\
\text { pain) }\end{array}$ & $\begin{array}{l}\text { Non-significant } \\
\text { reduction in groin injury } \\
\text { by } 31 \%\end{array}$ \\
\hline $\begin{array}{l}\text { Comin } \\
\text { et } a^{37}\end{array}$ & $\begin{array}{l}\text { RFD of ilioinguinal } \\
\text { nerve with local } \\
\text { anaesthesia and } \\
\text { steroid injections }\end{array}$ & $\begin{array}{l}36 \text { (pain arising } \\
\text { from medial } \\
\text { aspect of } \\
\text { inguinal } \\
\text { ligament) }\end{array}$ & $\begin{array}{l}\text { Improvement with RFD } \\
(\mathrm{p}<0.001)\end{array}$ \\
\hline
\end{tabular}

RFD, radiofrequency denervation; TEP, totally extraperitoneal.

Certainly, a laparoscopic approach should provide a quicker return to full sporting activity as propagated by others advocating this technique. ${ }^{184142}$ However, critics of the laparoscopic technique emphasise that the pathology present can only be viewed and treated by the anterior approach as it may involve the rectus abdominis muscle origin on the pubic bone as well as at the conjoint tendon with increased tension on the ilioinguinal and genitofemoral nerves which must also be released. ${ }^{1}$ However in contrast, a more recently published study has postulated that most of the symptoms relate to inguinal ligament pathology and advocates dividing the ligament laparoscopically with reinforcing the groin using a mesh. ${ }^{41}$ This report considers this abnormality to be analogous to that found in 'tennis elbow' and that symptoms improve by releasing the ligament from the pubic tubercle. Indeed histological abnormalities of the inguinal ligament enthesis have been documented in some athletes. ${ }^{21}$

\section{Consensus presentations}

Four presentations were given by four surgeons with a proven record of research in groin pain cumulating to a total of 90 years of experience. Two surgeons had a large experience in the open surgical technique; one utilised a conventional Lichtenstein operation with a tension-free mesh repair and the other utilised a suture 'darn' technique. Both surgeons accepted that there was undue 'stress' on the pubic bone which created 'tension' that resulted in the pain experienced by the athlete. Their respective techniques allowed a 'release' in the tension in the inguinal canal with any weakness reinforced by the repair method chosen (darn or mesh). In terms of the tension in the groin it was understood that this analysis was based on experience and therefore subjective rather than based on any scientific test or measurable finding. The third surgeon favoured a laparoscopic transabdominal preperitoneal (TAPP) approach, where 'damage' or 'disruption' to the inguinal ligament was described. ${ }^{21}$ The damage caused by the tension in the inguinal ligament attachment was 'released' or divided and the posterior inguinal canal reinforced using a mesh. Tears to the inguinal ligament are a common finding in patients with pain arising from the pubic tubercle and disrupted collagen fibres have been 
found at microscopy. The fourth surgeon had over 15 years experience in the TEP technique introducing mesh behind the 'injured' groin. After dissection, the retropubic area was covered with a $10 \times 15 \mathrm{~cm}$ heavy or light polypropylene mesh. The procedure was often carried out bilaterally even if the symptoms were unilateral, because of the scarring caused by dissection in the preperitoneal space may have prevented a later operation of the non-affected contralateral side. The results of operative treatment from this single centre have been previously reported as good to excellent for 70-90\% of patients. ${ }^{10} 1832$

There was universal acceptance on a multidisciplinary assessment and approach to the athlete. All speakers agreed that this was a predominantly a male athlete phenomenon with only $1-3 \%$ of affected being female. Surgery is indicated only when there is failure of conservative measures and physiotherapy with pinpoint groin tenderness over the superficial inguinal ligament which is almost exclusively seen in all athletes.

Up to $40 \%$ of referred athletes also had coexisting adductor longus tendon disruption, but only $18 \%$ of these require any surgical intervention with an adductor tenotomy which was diagnosed clinically and by MRI. ${ }^{43}$ Adductor tenotomy should be undertaken if the main component of the pain is clinically diagnosed as originating from the adductor tendon. This can be determined by a sharp or heavy pain sensation on palpation of the adductor tendon origin which can be associated with oedema on MRI. Most athletes are well served with intensive adductor muscle physiotherapy or corticosteroid injections and it was recommended that the management of these particular athletes was conducted in conjunction with an orthopaedic surgeon. Up to $3 \%$ of athletes reported recurrent groin pain within 5 years from the largest series with $10 \%$ reporting pain on the non-operative side within 10 years as described by one of the open surgeons (darn repair) reported experience. ${ }^{33}$

All surgeons concurred that there has been a general decreasing trend in referrals from physiotherapists for surgery due to improvements in diagnostic imaging and physiotherapy regimes. This finding has also been confirmed by a large reported experience in the treatment of this condition over two decades. ${ }^{44}$

In the surgeons' experience there was a consensus that footballers, ice-hockey players, rugby players, fast bowlers in cricket and middle-distant runners are most likely to be affected by this condition with swimmers, cyclists and especially boxers less likely to experience the symptoms. ${ }^{18} 213233$

The discussion with respect to the need for surgery ended with the agreement that careful selection, a multidisciplinary approach, accurate diagnosis, good surgical technique and vigorous rehabilitation are essential in the management of SG. Indeed it was noted by all surgeons that only $60 \%$ of elite athletes referred were being offered surgery.

Complications of surgery were discussed generally with no specific attention to either laparoscopic or open operative techniques. The majority of athletes that undergo surgery (approximately 90\%) should have few or no complications, with the main risks including infection and/or bleeding in 3-5\% and a predicted failure, that is the pain will recur, in about $10 \%$ of individuals that undergo surgery.

\section{Question 5 response-If yes to surgery then what operation should be undertaken?}

The panellist based their respective views to this question on their own experiences. However, it was accepted that to date that there has been no randomised controlled trial (RCT) comparing different surgical approaches used to treat ID. There was also no clear opinion on whether an open (anterior) approach ${ }^{33}$ or laparoscopic (posterior) approach ${ }^{18} 21$ should be used. Both techniques described by the surgeons commented on the pathology present. The pathology included tears in the inguinal ligament and conjoint tendon. ${ }^{18} 213233$

In one operation, abnormalities of the inguinal ligament are identified and the inguinal ligament released from the pubic tubercle together with some fibres of the conjoint tendon and pectineal fascia. A TAPP repair using a soft polyester mesh (the choice of mesh type is made by the surgeon) is then performed. The inguinal ligament 'release procedure' has been reported to have very acceptable results. ${ }^{41}$

With the open technique reference was made to a weakness in the posterior wall with an increase in tension in the inguinal ligament. In an attempt to release the tension some fibres of the conjoint tendon were divided together with an adductor muscle tenotomy and subsequent reconstruction with a mesh. A formal release of the inguinal ligament can only be performed laparoscopically as an open release would risk the development of a femoral hernia.

Repair of the ID can be carried out by either open or laparoscopic technique with the surgeon advised to use his/her own preferred method. With all repairs it was recognised to identify the anatomy and release any abnormal tension in the inguinal ligament. Any resultant defects or weaknesses created should be repaired or reinforced with a mesh.

It was noted that the laparoscopic technique had a quicker recovery and return to sporting activity, ${ }^{8} 9$ but it was also accepted that the surgeon's relative expertise and experience in a particular technique was a major determining factor in the type of repair undertaken. Furthermore, there was no RCT data to suggest that any technique was superior.

The consensus panellist included two surgeons (IM, OJG) that carried out an open technique, one using a mesh and the other a simple darn. The laparoscopic surgeons (DML and HP) using TAPP and TEP techniques with the one surgeon using both laparoscopic and open techniques (AJS).

\section{Question 6 response-What other treatment modalities would you use?}

This question was designed specifically to determine whether any other modalities other than surgery were successfully used by the panellists. No agreement was reached in this area with suggestions of steroid injections, active physiotherapy and prolotherapy offered to the panellists as possibilities. There was a general consensus that support of an orthopaedic surgeon and an experienced physiotherapist is needed as well as radiological input mainly to exclude other pathologies. It was also reaffirmed that approximately $20 \%$ of athletes needed an adductor tenotomy which, was diagnosed clinically and by MRI. The importance of a multidisciplinary approach with an orthopaedic surgeon was emphasised in this question.

\section{Question 7 response-What repair would you undertake for a primary presentation?}

Before the conference, all the surgeons agreed that there may be a difference in their respective approaches for an initial presentation and a recurrence. As per question 5 there remained the expressed opinion that the surgeon's initial choice of repair depends on his/her expertise.

\section{Question 8 response-What repair or management would you recommend for a recurrence?}

There was no general consensus for treating recurrent pain and the choice of surgery or repair was recommended based on the 
surgeon's experience in managing recurrent groin pain with operative and non-operative techniques. It was also recognised that with recurring symptoms of pain the athlete may well choose to obtain an opinion from another surgeon who may then choose to reoperate on the individual with his/her own technique especially if it differs from the initial technique used and as a consequence, the surgeons were not always aware of all their respective recurrences.

\section{Summary of surgery}

The surgeon's choice of repair relies on his/her expertise as to whether to use an open or laparoscopic (TAPP or TEP) technique. $^{21} 32$ The surgery itself relies on identifying pathology, releasing any abnormal tension and restoring anatomy with suture or mesh reinforcement. There is no evidence from RCT to support the superiority of any type of operation.

\section{Further discussion}

It was agreed that there should be a national registry for all ID repairs especially in professional sportsmen. The registry should include all the investigations carried out, pathology identified as well as treatment undertaken including physiotherapy, injection therapy and details of any surgery undertaken. The registry should also include follow-up data and documentation of any recurrent symptoms which may then be used to possibly aid in determining which operations can be recommended in the future. Any present national registry that already exists for example the Scandinavian Registry should also possibly be incorporated. A possible treatment algorithm was summarised in table 2 .

\section{Consensus summary}

ID is a condition recognised by groin pain and is commonly seen in very active sports persons. It can be defined as pain in the inguinal region near the pubic tubercle, which may have an insidious or acute onset and where no obvious other pathology exists to explain the symptoms. The experts have agreed that an experienced multidisciplinary approach is required with a physiotherapist, orthopaedic and a hernia surgeon being the key members. Radiological imaging is now required in many cases to exclude other conditions.

ID in elite athletes requires careful examination and assessment and it should be noted that surgery is only required in approximately $60 \%$ of cases and must be preceded by appropriate physiotherapy (see box 1) to improve core stability. Surgery to date has aimed at treating the injury, which has failed to respond to conservative measures such as rest, structured exercises, physiotherapy, anti-inflammatory medication and local anaesthetic plus steroid injections. ${ }^{45}$

In terms of the surgery and operative approach, this should be dependent on the surgeon's experience.

\section{Consensus conclusion}

The consensus panellists recognised that chronic pain in the groin experienced by athletes is a difficult field with many differing opinions with the type of surgery undertaken based on the surgeon's relative expertise.

The consensus meeting's main strength was the presence of recognised leading surgeons in the field of SG in open and minimal access techniques. Another valued strength was the multidisciplinary opinions of a specialist chartered physiotherapist from a professional football club as well as a leading musculoskeletal radiologist.
A weakness of the consensus was however, the paucity of data from the literature to help substantiate the various opinions as well as the lack of RCT evidence to support any firm surgical recommendations.

This statement should not be regarded as evidence but a best guide in this area of clinical practice.

\section{In summary}

A. Preferred terminology should be ID;

B. ID can be defined as pain, either of an insidious or acute onset, which occurs predominantly in the groin area near the pubic tubercle where no obvious other pathology, such as a hernia, exists to explain the symptoms.

The diagnosis of ID can be made if at least three of the five clinical signs below are detectable:

1. Pinpoint tenderness over the pubic tubercle at the point of insertion of the conjoint tendon;

2. Palpable tenderness over the deep inguinal ring;

3. Pain and/or dilation of the external ring with no obvious hernia evident;

4. Pain at the origin of the adductor longus tendon;

5. Dull, diffuse pain in the groin, often radiating to the perineum and inner thigh or across the midline.

C. The initial history and examination remains a key with a full physiotherapy rehabilitation regime undertaken prior to any surgery contemplated.

D. Imaging is recommended for all patients with ID as it will be important to exclude other conditions that may cause chronic groin pain.

E. Any surgery should be carried out as part of a dedicated team; the role of surgery is to release the abnormal tension in the inguinal canal and reconstruct the weakness in the posterior wall when other conservative approaches have failed.

\section{Future direction}

The panellists accept that research is needed across a range of areas in order to answer some critical research questions.

The panellists also accept that there are limitations with this document as the audience was predominantly from the surgical discipline. A greater multidisciplinary panel will therefore be required for any future consensus with the aim to provide recommendations for the management of ID.

The key areas for research identified include:

1. A clearer algorithm on what specific findings on MRI would constitute a definition of ID;

2. Evidence-based treatment algorithm on the length of conservative measures and physiotherapy regimes followed by indications for surgery and if possible the type of surgery recommended;

3. Physiotherapy regime descriptions to suit differing surgical techniques should be explored and commented on.

4. Differing surgical techniques should be tested in multicentred RCT by surgeons possessing expertise in open and laparoscopic techniques.

5. A national registry should be established.

\section{Author affiliations}

'Department of Surgery, Central Manchester Foundation Trust, Manchester Royal Infirmary, Manchester, UK

${ }^{2}$ Department of Surgery, Royal Gwent Hospital, Newport, UK

${ }^{3}$ Department of Surgery, Leicester General Hospital, Leicester, UK

${ }^{4}$ Department of Musculoskeletal Radiology, Leeds Teaching Hospitals, Chapel

Allerton Hospital, Leeds, UK

${ }^{5}$ Department of Sports Medicine, Blackburn Rovers STC, Blackburn, UK 
${ }^{6}$ Department of Surgery, Kuopio University Hospital, University of Eastern Finland, Kuopio, Finland

${ }^{7}$ Department of General Surgery, Royal Infirmary of Edinburgh, Edinburgh, UK

${ }^{8}$ Department of Surgery, Derriford Hospital, Plymouth, UK

${ }^{9}$ Department of Surgery, Gilmore Groin and Hernia Clinic, London, UK

${ }^{10}$ Department of Surgery, Royal Bournemouth Hospital, Bournemouth, UK

${ }^{11}$ Department of Surgery, Western Infirmary, Glasgow, UK

${ }^{12}$ Department of Surgery, London Hernia Centre, London, UK

\section{Competing interests None.}

Provenance and peer review Not commissioned; externally peer reviewed.

Open Access This is an Open Access article distributed in accordance with the Creative Commons Attribution Non Commercial (CC BY-NC 3.0) license, which permits others to distribute, remix, adapt, build upon this work non-commercially, and license their derivative works on different terms, provided the original work is properly cited and the use is non-commercial. See: http://creativecommons.org/ licenses/by-nc/3.0/

\section{REFERENCES}

1 Campanelli G. Pubic inguinal pain syndrome: the so-called sports hernia. Hernia 2010;14:1-4.

2 Hackney RG. The sports hernia: a cause of chronic groin pain. Br I Sports Med 1993;27:58-62.

3 Swan KG, Wolcott M. The athletic hernia: a systematic review. Clin Orthop Relat Res 2007:455:78-87.

4 Harmon KG. Evaluation of groin pain in athletes. Curr Sports Med Rep 2007:6:354-61.

5 Farber AJ, Wilckens JH. Sports hernia: diagnosis and therapeutic approach. J Am Acad Orthop Surg 2007;15:507-14.

6 Diesen DL, Pappas TN. Sports hernias. Adv Surg 2007:41:177-87.

7 Falvey EC, Franklyn-Miller A, McCrory PR. The groin triangle: a patho-anatomical approach to the diagnosis of chronic groin pain in athletes. $\mathrm{Br}$ J Sports Med 2009;43:213-20.

8 Caudill $\mathrm{P}$, Nyland J, Smith C, et al. Sports hernias: a systematic literature review. $\mathrm{Br}$ J Sports Med 2008;42:954-64.

9 Jansen JA, Mens JM, Backx FJ, et al. Treatment of longstanding groin pain in athletes: a systematic review. Scand J Med Sci Sports 2008;18:263-74.

10 Paajanen $\mathrm{H}$, Brinck T, Hermunen $\mathrm{H}$, et al. Laparoscopic surgery for chronic groin pain in athletes is more effective than nonoperative treatment: a randomised clinical trial with magnetic resonance imaging of 60 patients with sportsman's hernia (athletic pubalgia). Surgery 2011:150:99-107.

11 Robinson P, Barron DA, Parsons W, et al. Adductor-related groin pain in athletes: correlation of MR imaging with clinical findings. Skeletal Radiol 2004;33:451-7.

12 Robinson $\mathrm{P}$, Bhat $\mathrm{V}$, English B. Imaging in the assessment and management of athletic pubalgia. Semin Musculoskelet Radiol 2011:15:14-26.

13 Brennan D, O'Connell MJ, Ryan M, et al. Secondary cleft sign as a marker of injury in athletes with groin pain: MR image appearance and interpretation. Radiology 2005;235:162-7.

14 Koulouris G. Imaging review of groin pain in elite athletes: an anatomic approach to imaging findings. AJR Am J Roentgenol 2008;191:962-72.

15 Paajanen $\mathrm{H}$, Hermunen $\mathrm{H}$, Karonen J. Pubic magnetic resonance imaging findings in surgically and conservatively treated athletes with osteitis pubis compared to asymptomatic athletes during heavy training. Am J Sports Med 2008;36:117-21.

16 Beatty T. Osteitis pubis in athletes. Curr Sports Med Rep 2012;11:96-8.

17 Cunningham PM, Brennan D, O'Connell M, et al. Patterns of bone and soft-tissue injury at the symphysis pubis in soccer players: observations at MRI. AJR Am J Roentgenol 2007;188:W291-6.

18 Susmallian S, Ezri T, Elis M, et al. Laparoscopic repair of 'sportsman's hernia' in soccer players as treatment of chronic inguinal pain. Med Sci Monit 2004;10: CR52-4.

19 Kesek P, Ekberg O, Westlin N. Herniographic findings in athletes with unclear groin pain. Acta Radiol 2002;43:603-8.
20 Polglase AL, Frydman GM, Farmer KC. Inguinal surgery for debilitating chronic groin pain in athletes. Med J Aust 1991;155:674-7.

21 Mann $C D$, Sutton $C D$, Garcea $G$, et al. The inguinal release procedure for groin pain: initial experience in 73 sportsmen/women. Br J Sports Med 2009;43:579-83.

22 Larson CM, Pierce BR, Giveans MR. Treatment of athletes with symptomatic intra-articular hip pathology and athletic pubalgia/sports hernia: a case series. Arthroscopy 2011;27:768-75.

23 Fredberg U, Kissmeyer-Nielsen P. The sportsman's hernia-fact or fiction? Scand J Med Sci Sports 1996:6:201-4.

24 Robinson P. Sonography of common tendon injuries. AJR Am J Roentgenol 2009;193:607-18.

25 Robinson $\mathrm{P}$, Hensor $\mathrm{E}$, Lansdown MJ, et al. Inquinofemoral hernia: accuracy of sonography in patients with indeterminate clinical features. AJR Am J Roentgenol 2006:187:1168-78.

26 Steele P, Annear P, Grove JR. Surgery for posterior inguinal wall deficiency in athletes. J Sci Med Sport 2004;7:415-21; discussion 422-3.

27 Holt MA, Keene JS, Graf BK, et al. Treatment of osteitis pubis in athletes. Results of corticosteroid injections. Am J Sports Med 1995:23:601-6.

28 Schilders E, Bismil Q, Robinson P, et al. Adductor-related groin pain in competitive athletes. Role of adductor enthesis, magnetic resonance imaging, and entheseal pubic cleft injections. J Bone Joint Surg Am 2007:89:2173-8.

29 Zoga AC, Mullens FE, Meyers WC. The spectrum of MR imaging in athletic pubalgia. Radiol Clin North Am 2010;48:1179-97.

30 Dostal WF, Soderberg GL, Andrews JG. Actions of hip muscles. Phys Ther 1986;66:351-61.

31 Macintyre J, Johson C, Schroeder EL. Groin pain in athletes. Curr Sports Med Rep 2006:5:293-9

32 Paajanen H, Syvähuoko I, Airo I. Totally extraperitoneal endoscopic (TEP) treatment of sportsman's hernia. Surg Laparosc Endosc Percutan Tech 2004;14:215-18.

33 Gilmore OJA. Gilmore's groin: ten years experience of groin disruption-a previously unsolved problem in sportsmen. Sports Med Soft Tissue Trauma 1991;3:12-14.

34 Hölmich P, Uhrskou P, Ulnits L, et al. Effectiveness of active physical training as treatment for long-standing adductor-related groin pain in athletes: randomised trial. Lancet 1999:353:439-43.

35 Hölmich P, Larsen K, Krogsgaard K, et al. Exercise program for prevention of groin pain in football players: a cluster-randomised trial. Scand J Med Sci Sports 2010;20:814-21

36 Weir A, Jansen JA, van de Port IG, et al. Manual or exercise therapy for long-standing adductor-related groin pain: a randomised controlled clinical trial. Man Ther 2011:16:148-54.

37 Comin J, Obaid H, Lammers $\mathrm{G}$, et al. Radiofrequency denervation of the inguinal ligament for the treatment of 'sportsman's hernia': a pilot study. Br J Sports Med 2013:47:380-6.

38 Muschaweck U, Berger L. Minimal repair technique of sportsmen's groin: an innovative open-suture repair to treat chronic inguinal pain. Hernia 2010;14:27-33.

39 Muschaweck U, Berger LM. Sportsmen's groin-diagnostic approach and treatment with the minimal repair technique: a single-center uncontrolled clinical review. Sports Health 2010;2:216-21.

40 Minnich JM, Hanks JB, Muschaweck U, et al. Sports hernia: diagnosis and treatment highlighting a minimal repair surgical technique. Am J Sports Med 2011;39:1341-9

41 Lloyd DM, Sutton CD, Altafa A, et al. Laparoscopic inguinal ligament tenotomy and mesh reinforcement of the anterior abdominal wall: a new approach for the management of chronic groin pain. Surg Laparosc Endosc Percutan Tech 2008;18:363-8.

42 Srinivasan A, Schuricht A. Long-term follow-up of laparoscopic preperitoneal hernia repair in professional athletes. J Laparoendosc Adv Surg Tech A 2002;12:101-6.

43 Akermark C, Johansson C. Tenotomy of the adductor longus tendon in the treatment of chronic groin pain in athletes. Am J Sports Med 1992;20:640-3.

44 Meyers WC, McKechnie A, Philippon MJ, et al. Experience with 'sports hernia' spanning two decades. Ann Surg 2008;248:656-65.

45 Nam A, Brody F. Management and therapy for sports hernia. J Am Coll Surg 2008:206:154-64. 